УДК 316.34(470.12)

\title{
ПОВЫШЕНИЕ КАЧЕСТВА ЖИЗНИ РОССИЙСКИХ ГРАЖДАН - ПРИОРИТЕТНОЕ НАПРАВЛЕНИЕ ОБЕСПЕЧЕНИЯ ЭКОНОМИЧЕСКОЙ БЕЗОПАСНОСТИ
}

\author{
(C) 2012 г. Н. Л. Курепина, С. С. Барков
}

Московская академия экономики и права

В статье приведены данные об уровне и качестве жизни российских граждан, которые свидетельствуют о существующей потребности в обеспечении безопасности в целях снижения возможности негативного воздействия, повышения качества жизненных условий. Отмечено, что необходимо повысить уровень контроля качества продуктов питания.

Ключевые слова: экономическая безопасность; качество продуктов питания; уровень жизни; заболеваемость; технические регламенты.

The article reveals the data about standards and Russian residents' quality of life that indicate needs for ensuring the security for the purpose of decrease and possibility of negative influences and increasing the quality of living conditions. It's also shown that it's necessary to intensify the control of the food products quality.

Key words: economic safety; a quality offood products; living standard; sickness rate; technical regulations.

Уровень и качество жизни населения - один из основных показателей экономической безопасности страны. «Повышение качества жизни российских граждан путем гарантирования личной безопасности, а также высоких стандартов жизнеобеспечения», как отмечено в Стратегии национальной безопасности Российской Федерации, является стратегическим национальным приоритетом [1].

Уровень жизни населения определяется не только величиной доходов населения, их уровнем, но и качеством жизненных условий, качеством питания и другими показателями.

Мировая практика показывает, что угрозы экономической безопасности минимальны, когда удельный вес населения, имеющего доходы ниже прожиточного минимума, составляет 7-10\%. Уровень бедности (доля населения с доходами ниже прожиточного минимума) в России на протяжении последних лет варьировал от $29,0 \%$ в 2000 году до 12,7\% в 2011 году.

Более трети населения проживало в
2006 году за чертой бедности в республиках Тыва $(38,7 \%)$, Алтай $(37,8 \%)$, Адыгея $(34,3 \%)$, Ивановская область $(35,2 \%)$. В отдельных регионах половина населения имела денежные доходы ниже прожиточного минимума, это республики Ингушетия $(57,4 \%)$ и Калмыкия $(48,7 \%)$, Усть-Ордынский Бурятский $\mathrm{AO}(75,5 \%)$.

В последние годы по мере стабилизации и роста экономики бедность в России стала отступать, но этот процесс идет медленно, особенно в сельской местности. Сегодня, по официальным данным, бедными считаются 13,2\% населения страны. Кроме того, необходимо учитывать тот факт, что значительная часть населения имеет среднедушевые доходы, лишь немного превышающие порог бедности.

Принимаемые государством меры по повышению уровня жизни населения, социальная направленность программ позволили уменьшить долю населения, живущего за чертой бедности, однако в отдельных регионах данный показатель остается на высоком 
уровне: так, в 2011 году в республиках Калмыкия - 35,8\%, Тыва - 30,6\%, Марий Эл $24,2 \%$, Алтайском крае - 22,6\%, Амурской области - 20,4\% и в др. регионах, в которых уровень бедности остается на критически высоком уровне.

Падение жизненного уровня населения, снижение доходов отрицательно отразилось на структуре питания. По сравнению с рациональным потребительским бюджетом энергетическая ценность питания россиян значительно снизилась: так, калорийность питания $77,3 \%$, а также содержание основных питательных веществ: белков 73,3\%, жиров 76,4\% от нормы.

Особое беспокойство вызывает низкий уровень среднедушевого потребления белковых продуктов: мяса и мясопродуктов, молока и молочных продуктов, рыбы, яиц, несмотря на то, что в последние годы отмечается положительная динамика их потребления. Потребление данных продуктов значительно ниже физиологических норм потребления: так, потребление на душу населения в 2010 году составило: мяса - 71 кг или 87,7\%, молока - 246 кг или $62,8 \%$, яиц - 271 штук или $92,8 \%$.

Такое соотношение основных компонентов питания приводит к снижению работоспособности и устойчивости населения к неблагоприятным факторам внешней среды, росту заболеваемости, снижению продолжительности жизни и в итоге - к разрушению генофонда. Отсутствие сбалансированного питания является одной из причин возникновения среди населения алиментарно-зависимых заболеваний. Потребление на душу населения ниже рекомендуемого уровня мяса, молока и молочных продуктов, рыбы, яиц, овощей, фруктов, приводит к недостатку белка, витаминов - C, группы В, микроэлементов, энергии.

Особенно остро недостаток потребления белковых продуктов, молочных продуктов сказывается на здоровье детей, если для взрослого соблюдение рационально сбалансированного питания - это здоровье, долголетие, высокая работоспособность, то для детей это нормальное развитие, физическое и психическое здоровье на всю будущую жизнь.

По данным Министерства здравоохранения РФ [5] среди новорожденных детей наблюдается тенденция к увеличению числа родившихся с низким весом. Возросло число детей с низкими антропометрическими показателями.

Необходимо отметить, что проблема безопасности продуктов питания в России приобрела особую остроту в последние годы, что связано с увеличением поступления на продовольственный рынок некачественных, фальсифицированных и опасных для здоровья продуктов.

Исследования показывают, что произошли существенные сдвиги как в структуре потребления продуктов питания, так и в их качестве, появилась опасность попадания с пищей различных токсикантов химической и биологической природы, бесконтрольного распространения пищевой продукции, полученной из генетически модифицированных растений с использованием генетически модифицированных микроорганизмов и микроорганизмов, имеющих генетически модифицированные аналоги.

Было забраковано и снижено в сортности более $30 \%$ общего объема проинспектированных импортных продовольственных товаров: кондитерских изделий, продуктов детского питания, сыров, колбасных изделий и копченостей, рыбы и рыбопродуктов, масла животного происхождения.

Вызывает тревогу и качество питьевой воды. По данным Государственного доклада «О состоянии санитарно-эпидемиологического благополучия населения в Российской Федерации в 2011 году» на территориях 56 субъектов Российской Федерации питьевая вода не соответствовала гигиеническим нормативам по жесткости (2010 г. - 54 субъектов Российской Федерации; 2009 г. - 43 субъектов Российской Федерации). В 2009-2011 гг. более 30 млн. человек употребляли питьевую воду с общей жесткостью $\geq 10$ мг/экв./л [6].

Питьевую воду централизованных систем хозяйственно-питьевого водоснабжения, не отвечающую санитарным правилам и нормам по содержанию условно-патогенных и патогенных бактерий, потребляли более 23 млн. человек.

Негативное влияние совокупности экономических, социальных и медицинских факторов обуславливают рост количества хронически больных, неизбежно приводит к росту 
инвалидности среди трудоспособного населения. Данные статистики свидетельствуют о значительном росте уровня заболеваемости населения, в 2010 году общее число зарегистрированных заболеваний с впервые установленным диагнозом составило 779,6 на 1000 человек населения, что на 15,3\% выше уровня 1995 г., то в 2011 году соответственно 796,9 и 17,9\% (табл. 1).

При этом зарегистрирован рост числа заболеваемости по всем основным группам болезней.

По данным Государственного доклада о состоянии здоровья населения не снижается заболеваемость сердечно-сосудистыми, онкологическими болезнями, СПИДом, алкоголизмом, наркоманией.

Продолжительность жизни больных с хроническими заболеваниями органов дыхания в Российской Федерации на 10-15 лет меньше, чем в европейских странах.

Ухудшение состояние здоровья российского населения и возрастающая неполноценность питания по количеству и качеству потребляемых продуктов ведет к истощению человеческого потенциала российского населения, порождает социально-экономические проблемы.

Приведенные данные об уровне и качестве жизни российских граждан показали, что существует потребность в защите от нежелательных внешних воздействий, иначе говоря, потребность в безопасности, поэтому в целях снижения возможности негативного воздействия, повышения качества жизненных условий необходимо решение одной из первоочередных задач - повысить уровень контроля качества продуктов питания. Базисом обеспечения качества и безопасности продукции должна служить стройная система нормативно-технической документации.

Следует отметить, что за последнее время данная проблема нашла свое отражение в принятых законодательных актах.

Так в соответствии с законом «О санитарно-эпидемиологическом благополучии населения» [2] осуществляется контроль за контаминантами химической и биологической природы в продовольственном сырье и продуктах питания. Тем же законом, закреплены организационно-правовые меры обеспечения санитарно-эпидемиологического благополучия населения, одной из которых является сертификация продукции, работ и услуг, представляющих потенциальную опасность для человека.

Принят Федеральный закон от 27 декабря 2002 г. №184-Ф3 «О техническом регулировании» [3], на основании которого разработаны технические регламенты на молоко и мо-

Таблица 1

Заболеваемость на 1000 человек населения (зарегистрировано больных с диагнозом, установленным впервые в жизни) [7]

\begin{tabular}{|l|c|c|c|c|c|c|}
\hline & 1995 & 2000 & 2005 & 2010 & 2011 & $\begin{array}{c}2010 \\
\text { в \% } \\
\text { к 1995 г. }\end{array}$ \\
\hline Центральный & 667,7 & 708,5 & 706,5 & 719,0 & 734,7 & 110,0 \\
\hline Северо-Западный & 701,3 & 763,0 & 763,1 & 851,8 & 860,4 & 122,7 \\
\hline Южный & 579,6 & 641,9 & 680,9 & 685,3 & 709,6 & 122,4 \\
\hline Северо-Кавказский & 434,8 & 509,8 & 613,5 & 604,4 & 652,5 & 143,9 \\
\hline Приволжский & 743,2 & 798,0 & 809,2 & 867,6 & 877,9 & 118,1 \\
\hline Уральский & 707,5 & 791,1 & 779,9 & 814,0 & 823,2 & 116,4 \\
\hline Сибирский & 694,5 & 741,6 & 777,0 & 818,7 & 845,3 & 121,7 \\
\hline Дальневосточный & 720,5 & 740,9 & 755,6 & 830,6 & 838,1 & 116,3 \\
\hline Российская Федерация & 676,0 & 730,5 & 745,9 & 779,6 & 796,9 & 117,9 \\
\hline
\end{tabular}


лочную продукцию, на масложировую продукцию, на соковую продукцию из фруктов и овощей и др. виды продукции.

Технический регламент на молоко и молочную продукцию установил требования по безопасности к производству и специальным технологическим процессам, а также требования к производству, хранению, перевозке, реализации и утилизации молока и молокопродуктов, включая продукты детского питания на молочной основе [4].

Основной задачей разработки, принятия и введения в действие технических регламентов является установление с целью их соблюдения (а также, безусловно, возможности обеспечения контроля их соблюдения) требований по безопасности продукции и процессов производства, эксплуатации, хранения, перевозки, реализации и утилизации. Ведь в основе реформирования системы технического регулирования, осуществляемого в настоящее время в Российской Федерации, лежат исключительно соображения безопасности - для жизни и здоровья граждан, окружающей природной среды, животных и растений и др.

Необходимо, однако, отметить, что система нормативно-технической документации не будет иметь соответствующего эффекта без четко выработанных механизмов контроля и надзора за соблюдением технических регламентов, без усиления мер ответственности за их нарушение.

\section{Литература}

1. Указ Президента Российской Федерации от 12 мая 2009 г. №537 «О Стратегии национальной безопасности Российской Федерации до 2020 года».

2. Федеральный закон от 30 марта 1999 г. №52-Ф3 «О санитарно-эпидемиологическом благополучии населения». // СЗ РФ от 5 апреля 1999 г. №14, ст. 1650.

3. Федеральный закон от 27 декабря 2002 г. №184-Ф3 «О техническом регулировании». // С3 РФ от 30 декабря 2002 г. №52 (ч. 1), ст. 5140 .

4. Федеральный закон от 12 июня 2008 г. №88-Ф3 «Технический регламент на молоко и молочную продукцию». // СЗ РФ от 16 июня 2008 г. №24, ст. 2801.

5. Безопасность России. Правовые, социально-экономические и научно-технические аспекты. - М.: МГФ «Знание», 2001. $480 \mathrm{c}$.

6. О состоянии санитарно-эпидемиологического благополучия населения в Российской Федерации в 2011 году: Государственный доклад. - М.: Федеральный центр гигиены и эпидемиологии Роспотребнадзора, 2012. - $316 \mathrm{c}$.

7. Федеральная служба государственной статистики [Электронный ресурс] / Официальный сайт. - Режим доступа: http://www. gks.ru, свободный. - Загл. с экрана.

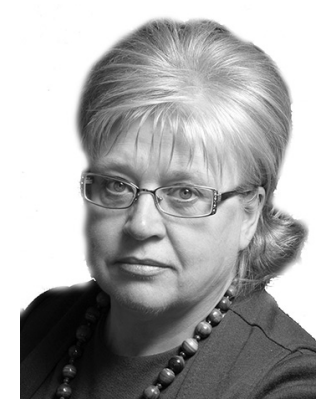

Наталья Леонидовна Курепина - доктор экономических наук, профессор Московской академии экономики и права.

Natalya Leonidovna Kurepina - Ph.D., Doctor of Economics, professor at The Moscow Academy of Economy and Law.

117105 , г. Москва, Варшавское ш., д. 25, Московская академия экономики и права 25 Varshavskoye hw., The Moscow Academy of Economy and Law, Moscow, Russia Тел.: +7 (910) 42-54-974; e-mail: kurepinanl@mail.ru 


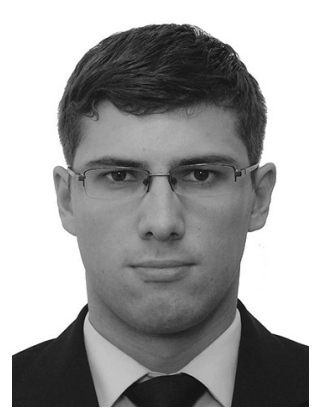

Сергей Сергеевич Барков - аспирант Московской академии экономики и права.

Sergey Sergeyevich Barkov — postgraduate student at The Moscow Academy of Economy and Law.

117105, г. Москва, Варшавское ш., д. 25, Московская академия экономики и права 25 Varshavskoye hw., The Moscow Academy of Economy and Law, Moscow, Russia Тел.: +7 (910) 42-54-974; e-mail: sbar81@gmail.com

\section{Гранты 2013 г. для исследователей по программе имени Марии Кюри (стажировки в Европе)}

Европейская Комиссия приглашает ученых к участию в финальном конкурсе на получение грантов по программе имени Марии Кюри (Marie Curie Actions). Около 227 миллионов евро, самая значительная сумма с момента начала Седьмой Рамочной программы (FP7, 2007-2013 гг) будет реализована в этом транше. Около тысячи ученых получат возможность участвовать в программе имени Марии Кюри в 2013 году.

C 14 марта 2013 в рамках Marie Curie Actions принимаются заявки от исследователей на получение грантов. К участию в конкурсе приглашаются ученые любой национальности, имеющие опыт исследовательской деятельности, планирующие участие в исследовательском проекте в стране $\mathrm{EC} / \mathrm{AC}$

Крайний срок приема заявок для участия в конкурсах - 14 августа 2013 года.

Подробно об участии в открытых конкурсах на сайте: http://ec.europa.eu/research/participants/portal/page/funding 